\title{
Substantivity of Carbodiimide Inhibition on Dentinal Enzyme Activity over Time
}

Mazzoni, A.

2017-07

Mazzoni , A , Angeloni , V , Sartori , N, Duarte , S, Maravic , T , Tjaderhane , L, Pashley ,

D H , Tay , F R \& Breschi , L 2017 , ' Substantivity of Carbodiimide Inhibition on Dentinal

Enzyme Activity over Time ' , Journal of Dental Research , vol. 96 , no. 8 , pp. 902-908 . https://doi.org/10.1177/0022

http://hdl.handle.net/10138/297800

https://doi.org/10.1177/0022034517708312

publishedVersion

Downloaded from Helda, University of Helsinki institutional repository.

This is an electronic reprint of the original article.

This reprint may differ from the original in pagination and typographic detail.

Please cite the original version. 


\title{
Substantivity of Carbodiimide Inhibition on Dentinal Enzyme Activity over Time
}

Journal of Dental Research 2017, Vol. 96(8) 902-908

(C) International \& American Associations for Dental Research 2017 Reprints and permissions: sagepub.com/journalsPermissions.nav DOI: $10.1177 / 0022034517708312$ journals.sagepub.com/home/jdr

\author{
A. Mazzoni', V. Angeloni', N. Sartori', S. Duarte Jr. ${ }^{2}$, T. Maravic', \\ L. Tjäderhane ${ }^{3,4}$, D.H. Pashley ${ }^{5}$, F.R. Tay, and L. Breschi'
}

\begin{abstract}
The use of I-ethyl-3-(3-dimethylaminopropyl) carbodiimide $\mathrm{HCl}$ (EDC) has recently been investigated for its effectiveness in the prevention of collagen degradation over time and the improvement of resin-dentin bond durability. The objective of the present study was to evaluate the effects of a $0.3 \mathrm{M}$ EDC-containing conditioner on endogenous enzymatic activities within the hybrid layer ( $\mathrm{HL}$ ) created by a self-etch or an etch-and-rinse adhesive after I y. The activity within the HL was examined using in situ zymography and confocal laser scanning microscopy after $24 \mathrm{~h}$ or I-y storage in artificial saliva. Dentin specimens were bonded with Clearfil SE Bond (CSE) or XP Bond (XPB). For CSE, the self-etching primer was applied and treated with $0.3 \mathrm{M} \mathrm{EDC} \mathrm{for} \mathrm{I} \mathrm{min,} \mathrm{and} \mathrm{then} \mathrm{the} \mathrm{bonding}$ agent was applied. For XPB, dentin was etched and treated with $0.3 \mathrm{M} \mathrm{EDC} \mathrm{for} \mathrm{I} \mathrm{min} \mathrm{and} \mathrm{then} \mathrm{bonded} \mathrm{with} \mathrm{the} \mathrm{primer-bonding}$ agent. Control specimens were prepared without EDC treatment. Slices containing the adhesive-dentin interface were covered with fluorescein-conjugated gelatin and observed with a multiphoton confocal microscope. Fluorescence intensity emitted by hydrolyzed fluorescein-conjugated gelatin was quantified, and the amount of gelatinolytic activity was represented by the percentage of green fluorescence emitted within the HL. After $24 \mathrm{~h}$ of storage, enzymatic activity was detected by in situ zymography within the HLs of both tested adhesives, with XPB higher than CSE $(P<0.05)$. Almost no fluorescence signal was detected when specimens were pretreated with EDC compared to controls $(P<0.05)$. After I y of storage, enzymatic activities significantly increased for all groups (excluding $X P B$ control) compared to 24 -h storage $(P<0.05)$, with EDC pretreated specimens exhibiting significantly lower activity than controls $(P<$ 0.05). The present study showed, for the first time, that the use of EDC for both the self-etch and the etch-and-rinse approaches results in the reduction but not complete inhibition of matrix-bound collagenolytic enzyme activities over time in the HL.
\end{abstract}

Keywords: matrix metalloproteinases, adhesives, collagen(s), dentin, enzymology, microscopy

\section{Introduction}

Significant advancements have been achieved in the field of adhesive dentistry over the past decade. Nevertheless, the hybrid layer (HL) remains the weakest link within the adhesivedentin interface created in tooth-colored restorations. The stability of resin-dentin bonds over time remains a formidable issue that has not been satisfactorily addressed.

Recent in vitro studies have demonstrated that the use of cross-linking agents can improve the short- and long-term mechanical properties of the demineralized dentin collagen matrix (Bedran-Russo et al. 2008, 2014; Castellan et al. 2011). These agents reduce the susceptibility of collagen fibrils to enzymatic degradation by collagenases and gelatinases (Scheffel, Hebling, Scheffel, Agee, Cadenaro, et al. 2014; SeseogullariDirihan et al. 2016) and increase the stability of the resindentin interface over time (Cova et al. 2011; Mazzoni et al. 2013). The application of contemporary dentin adhesives results in incomplete hybridization of the dentin substrate, leaving behind resin-sparse, unprotected collagen fibrils that are vulnerable to hydrolytic degradation. The denuded collagen fibrils are also exposed to additional degradation-promoting factors such as adhesive- or pulp-derived water that provide the functional environment for collagen-degrading enzymes, swelling of the resin polymer matrix, and channels for leaching of incompletely polymerized or degraded resinous components (Breschi et al. 2008; Liu et al. 2011; Matuda et al. 2016). Collectively, these factors contribute to the weakening of the adhesive joint between resin composites and dentin over time.

Previous work by various groups has identified the contribution of host-derived proteinases in the breakdown of denuded collagen matrices in incompletely infiltrated dentin HL (Pashley

\footnotetext{
'Department of Biomedical and Neuromotor Sciences, DIBINEM, University of Bologna-Alma Mater Studiorum, Bologna, Italy

${ }^{2}$ Division of Restorative Sciences, University of Southern California Herman Ostrow School of Dentistry, Los Angeles, CA, USA

${ }^{3}$ Department of Oral and Maxillofacial Diseases, University of Helsinki, and Helsinki University Hospital, Helsinki, Finland

${ }^{4}$ Research Unit of Oral Health Sciences, and Medical Research Center Oulu (MRC Oulu), Oulu University Hospital and University of Oulu, Oulu, Finland

${ }^{5}$ The Dental College of Georgia, Augusta University, Augusta, GA, USA

Corresponding Author:

L. Breschi, Department of Biomedical and Neuromotor Sciences, DIBINEM, University of Bologna-Alma Mater Studiorum, Via San Vitale 59, 40125, Bologna, Italy.

Email: Iorenzo.breschi@unibo.it
} 
et al. 2004; Mazzoni, Nascimento, et al. 2012; Tjäderhane et al. 2013). Among the matrix metalloproteinases (MMPs), MMP-2 and MMP-9 are involved in hydrolytic degradation of the dentin collagen matrix (Mazzoni, Nascimento, et al. 2012; Mazzoni, Scaffa, et al. 2012). Hence, inhibition of matrixbound collagenolytic enzymes is desirable for prolonging the longevity of resin-dentin bonds (Tjäderhane et al. 2013). Several synthetic MMP inhibitors have been employed experimentally during the formation of the resin-dentin interface with the intention of enhancing bond longevity. These MMP inhibitors include chlorhexidine, galardin, quaternary ammonium methacrylates, and various collagen crosslinking agents (Breschi et al. 2009; Breschi, Martin, et al. 2010; Breschi, Mazzoni, et al. 2010; Cova et al. 2011; Tezvergil-Mutluay et al. 2011; TezvergilMutluay et al. 2012; Breschi 2013; Mazzoni et al. 2013). Among these inhibitors, the use of collagen cross-linkers appears to be promising due to their synergistic action in strengthening type I collagen fibrils and reducing their biodegradation (Bedran-Russo et al. 2008; Frassetto et al. 2016; Hass et al. 2016; Seseogullari-Dirihan et al. 2016).

The collagen cross-linker 1-ethyl3-(3-dimethylaminopropyl) carbodiimide hydrochloride (EDC) is one of the most stable cyanamide isomers (Timkovich 1977). This zero-length cross-linking agent is also the most investigated collagen cross-linker due to its ability to cross-link peptides without introducing additional linkage groups (Lee et al. 1996). Recent in vitro studies have shown that application of EDC to acid-etched dentin for 1 min enhances the mechanical properties of dentin and inhibits soluble and matrix-bound MMPs (Tezvergil-Mutluay et al. 2012; Mazzoni et al. 2014; Scheffel, Hebling, Scheffel, Agee, Turco, et al. 2014). Application of EDC during etch-and-rinse bonding procedures stabilizes resin-dentin bond strength over time and results in a significant decrease of dentinal gelatinolytic activity within the HL (Mazzoni et al. 2013, 2014, 2015; Scheffel et al. 2015; Hass et al. 2016). Although these preliminary results are promising, information is lacking on the substantivity of EDC within the demineralized dentin collagen matrix and its capability in inhibiting dentin MMPs after long-term bond aging.

Accordingly, the objective of the present in vitro study was to evaluate the effects of using a therapeutic primer comprising $0.3 \mathrm{M} \mathrm{EDC}$, in conjunction with a 2-step self-etch or a 2-step etch-and-rinse adhesive, on endogenous enzymatic activities within the HL after $1 \mathrm{y}$ of storage in artificial saliva. The null hypotheses tested were that 1 ) the use of $0.3 \mathrm{M}$ EDC has no effect on inhibiting matrix-bound enzymatic activity within the
HL over time, and 2) enzymatic activities within the HL created by both self-etch and etch-and-rinse adhesives do not increase following aging of the resin-dentin bonds.

\section{Materials and Methods}

\section{Bonding Procedures}

Twenty extracted human third molars were obtained from anonymous individuals (age: 19 to 43 y; used within $1 \mathrm{wk}$ after extraction) following their informed consent for the use of teeth for the experiments. Enamel and cementum were removed, prior to the retrieval of a 1-mm-thick disk derived from mid-coronal dentin, using a slow-speed diamond saw (Micromet; Remet) under copious water cooling. A standardized smear layer was created with 320-grit wet silicon carbide paper. The dentin disks were randomly divided into 4 groups and treated as follows:

Group 1 (G1): Clearfil SE Bond (CSE; Kuraray Noritake Dental, Inc.) primer was applied on smear-layer covered dentin for $20 \mathrm{~s}$ and dried with mild airflow. The primed dentin was subsequently treated with $0.3 \mathrm{M} \mathrm{EDC}$ aqueous 


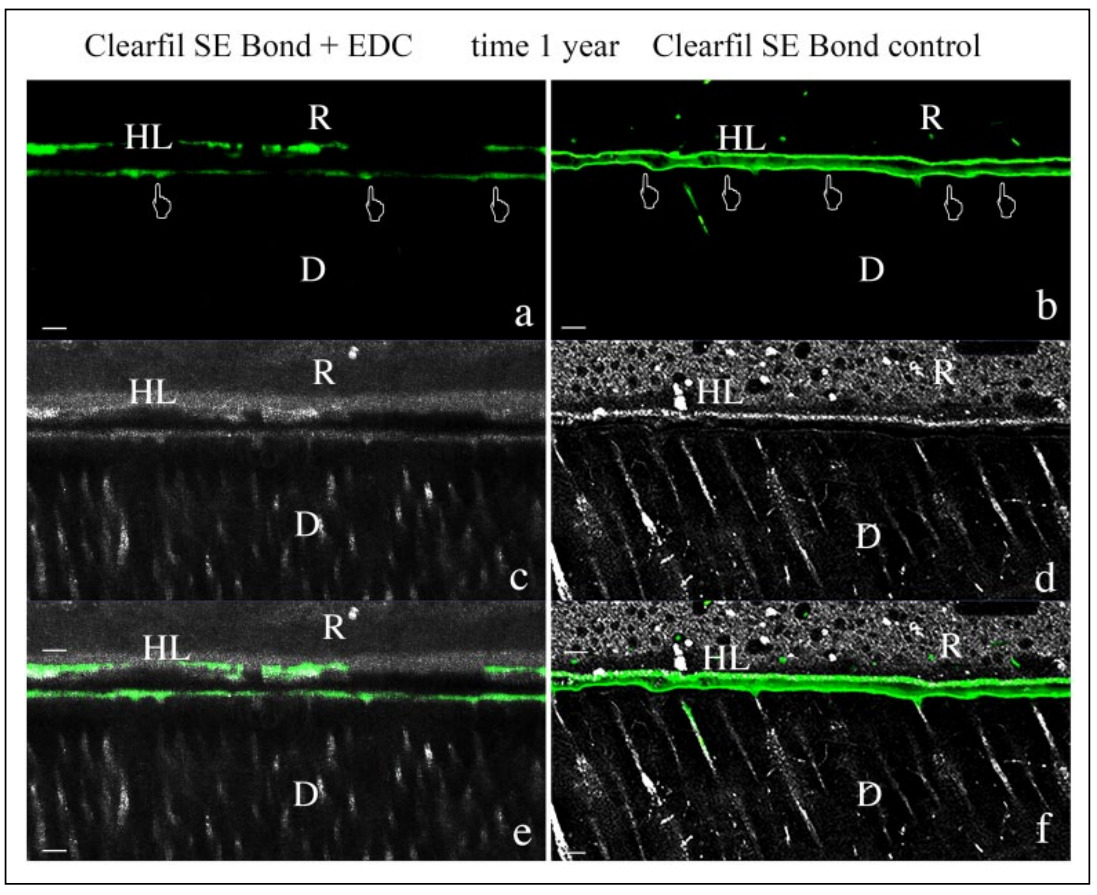

Figure 2. Resin-bonded dentin interfaces prepared with Clearfil SE (CSE) with or without I-ethyl-3-(3-dimethylaminopropyl) carbodiimide $\mathrm{HCl}(\mathrm{EDC})$ pretreatment after I y of storage $\left(T_{1 y}\right)$, incubated with quenched fluorescein-labeled gelatin. $D$, dentin; $H L$, hybrid layer; $R$, resin composite; bars $=5 \mu \mathrm{m}$. (a) Zymogram confocal image acquired in green channel of $\mathrm{HL}$ created with CSE applied to dentin pretreated with EDC showing weaker and discontinuous fluorescence (pointers). (b) Image acquired in green channel, showing intense and continuous fluorescence (identifying endogenous enzymatic activity) within the $\mathrm{HL}$ (pointers) created with CSE without EDC pretreatment. (c) Image of $\mathrm{HL}$ created with CSE after EDC pretreatment acquired as optical microscope showing the morphology of the HL. (d) Image of HL created with CSE after EDC pretreatment acquired as optical microscope. (e) Image of HL created with CSE after EDC pretreatment obtained by merging differential interference contrast image (showing the optical density of the resin-dentin interface) and image acquired in green channel (showing enzymatic activity). (f) Image of CSE without EDC pretreatment, obtained by merging differential interference contrast image as for (e) and image acquired in green channel (showing enzymatic activity)

solution for $1 \mathrm{~min}$ and gently air-dried. This was followed by CSE bond application.

Group 2 (G2): CSE primer and CSE bonding agent were sequentially applied on dentin in accordance with the manufacturer's instructions (CSE control group; i.e., without EDC pretreatment).

Group 3 (G3): Dentin disks were etched with 35\% phosphoric acid gel (3M ESPE) for $15 \mathrm{~s}$, rinsed with water, and treated with $0.3 \mathrm{M} \mathrm{EDC}$ for $1 \mathrm{~min}$. The etch-and-primed dentin surface was air-dried and bonded with XP Bond (XPB; Dentsply Sirona).

Group 4 (G4): The XPB adhesive was applied on etched dentin without EDC pretreatment in accordance with the manufacturer's instructions (XPB control group).

After bonding, each specimen was light-cured for $10 \mathrm{~s}$ using a light emission diode curing unit (Demi Plus; Kerr Corp.). A 1-mm-thick layer of flowable resin composite (Filtek Flow; 3 M ESPE) was applied to the resin-bonded disks and light-cured for $20 \mathrm{~s}$. Each bonded specimen was sectioned vertically into 1 -mm-thick slabs to expose the adhesive-dentin interface using the Micromet diamond saw under water cooling. The slabs were stored for $24 \mathrm{~h}$ $\left(\mathrm{T}_{0}\right)$ and $1 \mathrm{y}\left(\mathrm{T}_{1 \mathrm{y}}\right)$ at $37^{\circ} \mathrm{C}$ in artificial saliva (aging medium was refreshed every 2 wk) prepared using the formula previously employed by Pashley et al. (2004).

\section{In Situ Zymography}

The procedures were performed using the method reported by Mazzoni, Nascimento, et al. (2012) and Mazzoni et al. (2014). After aging for the designated period, each bonded slab was glued to a glass slide and polished to produce an approximately $40-\mu \mathrm{m}$-thick section. To produce the substrate, $1.0 \mathrm{mg} / \mathrm{mL}$ of a stock solution containing self-quenched fluoresceinconjugated gelatin (E-12055; Molecular Probes) was prepared by adding $1.0 \mathrm{~mL}$ deionized water to the vial containing the lyophilized gelatin. The substrate was stored at $-20^{\circ} \mathrm{C}$ until use. The gelatin stock solution was diluted 10 times with dilution buffer $\left(\mathrm{NaCl} 150 \mathrm{~mm}, \mathrm{CaCl}_{2} 5\right.$ $\mathrm{mm}$, Tris-HCl $50 \mathrm{~mm}, \mathrm{pH} \mathrm{8.0),} \mathrm{followed}$ by the addition of an antifading agent (Vectashield mounting medium with 4',6-diamidino-2-phenylindole [DAPI]; Vector Laboratories). Then, $50 \mu \mathrm{L}$ of the fluorescent gelatin mixture was placed on top of each polished dentin section and protected with a cover slip. The glass slide assemblies were light protected and incubated in a humidified chamber at $37^{\circ} \mathrm{C}$ for $48 \mathrm{~h}$.

Detection of endogenous gelatinolytic enzyme activity within the HL was based on hydrolysis of the quenched fluoresceinconjugated gelatin substrate. The process was evaluated by examining the glass slides with a multiphoton confocal laser scanning microscope (LSM 5 Pascal; Carl Zeiss), using an excitation wavelength of $495 \mathrm{~nm}$ and an emission wavelength of 515 $\mathrm{nm}$. Sixteen to 20 optical sections ( $350 \mathrm{~nm}$ thick) were acquired from different focal planes for each specimen. The stacked images were analyzed, quantified, and processed with ZEN 2009 software (Carl Zeiss). The fluorescence intensity emitted by the hydrolyzed fluorescein-conjugated gelatin was isolated and quantified using Image $\mathbf{J}$ (ImageJ; National Institutes of Health). The amount of gelatinolytic activity was expressed as a percentage of the green fluorescence within the HL.

Negative control sections were similarly incubated, with the exception that 1) $250 \mathrm{~mm}$ ethylenediaminetetraacetic acid (EDTA) was dissolved in the mixture of quenched fluoresceinconjugated gelatin, or 2) $2 \mathrm{~mm} \mathrm{1,10-phenanthroline,} \mathrm{or} \mathrm{3)} \mathrm{stan-}$ dard nonfluorescent gelatin instead of fluorescent-conjugated gelatin was used. The EDTA- and 1,10-phenanthrolinecontaining gelatin were used as negative controls. 


\section{Statistical Analysis}

The percentage of gelatinolytic activity was verified for normality of data distribution using the Shapiro-Wilk test $(P=0.468)$ and Levene test for homogeneity of variances $(P$ $=0.082)$. A 3-factor analysis of variance was then employed to examine the effects of EDC pretreatment, adhesive system, and storage time. The interaction among the 3 variables on the percentages of HL exhibiting gelatinolytic activities was also evaluated. Post hoc pairwise comparisons were performed using the Tukey honestly significant difference (HSD) test. For all analyses, statistical significance was preset at $\alpha=0.05$ (SPSS 19; SPSS, Inc.).

\section{Results}

Representative images of the 4 groups are reported in Figures 1 to 4, and percentages of HLs exhibiting hydrolysis of the quenched fluorescein-conjugated gelatin in the 4 groups $\left(\mathrm{T}_{0}\right.$ and $\mathrm{T}_{1 \mathrm{y}}$ aging in artificial saliva) are shown in the Table.

Bonded dentin slabs at $\mathrm{T}_{0}$ revealed almost no green fluorescence within the HLs created by CSE when EDC was applied as additional primer (G1), indicating complete inhibition of gelatinase activity (Fig. 1a, c, e). In control samples without EDC pretreatment, intermittent fluorescence in the HL indicated gelatinolytic activity (Fig. 1b, d, f; Table). With XPB adhesive, EDC pretreatment resulted in weak gelatinolytic activity in the HL (Fig. 3a, c, e) that was about $80 \%$ less intense than in XPB control samples with relatively continuous HL gelatinolytic activity (Fig. 3b, d, f; Table). While the difference in activities between the adhesives was not significant with EDC pretreatment, XPB showed significantly more HL gelatinolytic activity than CSE in control samples $(P<0.05$; Table).

At $\mathrm{T}_{1 \mathrm{y}}$, EDC-pretreated specimens showed a statistically significant increase in the HL green fluorescence for both tested adhesives compared to $\mathrm{T}_{0}$ (G1 and G3; Fig. 2a, c, e; Fig. 4a, c, e; Table), while the 2 adhesives showed different trends of gelatinolytic expression after aging for control specimens (Fig. 2b, d, f; Fig. 4b, d, f). CSE-bonded control samples showed significantly increased gelatinolytic activity after aging (Fig. 2b, d, f), while no difference was found for XPB (Fig. 4b, d, f; Table).

No fluorescence was detected in negative controls, that is, 1) EDTA-treated 2) specimens incubated with $2 \mathrm{~mm} \mathrm{1,10-phenanth-}$ roline or 3) with standard nonfluorescent gelatin (data not shown).

\section{Discussion}

The results of the present study revealed that pretreatment of dentin with EDC reduced the gelatinolytic activity for CSE bonds by $99 \%$ or $69 \%$ and for XPB bonds by $81 \%$ or $43 \%$ (at $\mathrm{T}_{0}$ and $\mathrm{T}_{12}$, respectively), and thus the first hypothesis was rejected. Moreover, the enzymatic activity of EDC-pretreated interfaces created either by CSE or XPB significantly increased after aging $(P<0.05)$. Similarly, the CSE control showed a 4-fold increase in enzyme activity within the HL over time, while the gelatinolytic activity produced by XPB remained stable. Thus, the second hypothesis was partially accepted.

Both etch-and-rinse (Mazzoni et al. 2006) and self-etch (Nishitani et al. 2006) bonding procedures expose and activate dentin endogenous enzymes, which are able to cleave the unprotected collagen of the resin-dentin interface over time (Tjäderhane et al. 2013; Mazzoni et al. 2015).

Chlorhexidine has been used in vitro and in vivo to prevent the enzymatic degradation of the HL (Carrilho et al. 2007; Breschi, Mazzoni, et al. 2010; Breschi 2013), although its inhibitory effect may be lost in 1.5 to 2 y (Carrilho et al. 2010; Ricci et al. 2010). This led to the use of cross-linking agents like EDC to preserve the HL integrity over time (Bedran-Russo et al. 2010; Bedran-Russo et al. 2014; Liu et al. 2011; Tjäderhane et al. 2013; Frassetto et al. 2016). However, although a wide range of cross-linkers is available, their specific antienzymatic 


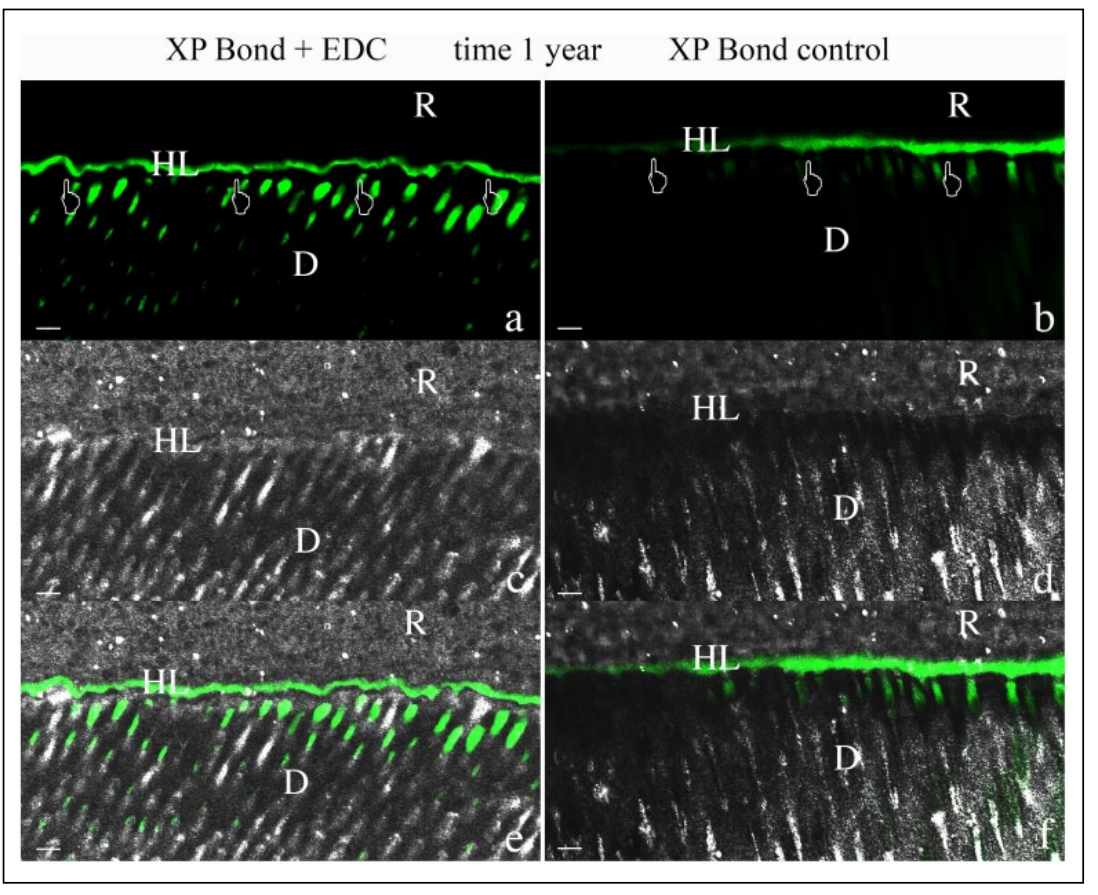

Figure 4. Resin-bonded dentin interfaces prepared with XP Bond (XPB) with or without I-ethyl-3-(3-dimethylaminopropyl) carbodiimide $\mathrm{HCl}$ (EDC) pretreatment and stored for I y $\left(T_{1}\right)$, incubated with quenched fluorescein-labeled gelatin. $D$, dentin; $H L$, hybrid layer; $R$, resin composite; bars $=5 \mu \mathrm{m}$. (a) Confocal image acquired in green channel of $\mathrm{HL}$ created with XPB applied to acid-etched dentin pretreated with EDC showing fluorescence within the $\mathrm{HL}$ (pointers) and dentinal tubule orifices. (b) Image acquired in green channel, showing fluorescence (identifying intense endogenous enzymatic activity) in dentinal tubule orifices and within the HL (pointers) created with XPB without EDC pretreatment. (c) Image of HL created with XPB after EDC pretreatment acquired as optical microscope showing the anatomy of the $\mathrm{HL}$. (d) Image of HL created with XPB without EDC acquired as optical image. (e) Image of $\mathrm{HL}$ created with XPB after EDC pretreatment obtained by merging differential interference contrast image (showing the optical density of the resin-dentin interface) and image acquired in green channel (showing enzymatic activity). (f) Image of XPB without EDC pretreatment, obtained by merging differential interference contrast image as for (e) and image acquired in green channel (showing enzymatic activity).

effects are still not clear. Among these cross-linkers, EDC pretreatment of demineralized dentin matrices increases the mechanical properties of the dentin matrix and also completely inhibits the endogenous protease activity (Tezvergil- Mutluay et al. 2012; Bedran-Russo et al. 2014). Zymographic studies, in fact, have shown that the pretreatment of acid-etched dentin with a conditioner containing $0.3 \mathrm{M}$ EDC could completely inhibit the collagenolytic activity of endogenous enzymes (Mazzoni et al. 2013), even after adhesive application (Mazzoni et al. 2014, 2015; Scheffel et al. 2015).

The localization of the activity detected by the in situ zymography in the control groups correlates well with the demineralized uninfiltrated collagen layer with etch-and-rinse and self-etch adhesives at the bottom of the HL, the same area known to express nanoleakage (Suppa et al. 2005) (Figs. 1b and $3 \mathrm{~b}$ ). In addition, with etch-and-rinse, adhesive activity was present at tubular orifices (Fig. 3b), presumably at the sites where tubular wall demineralization occurs. The effectiveness of EDC as a cross-linking primer before bonding was evident by the reduced protease activity at $T_{0}$ in both self-etch and etch-and-rinse groups (Figs. 1a and 3a). These findings correlate well with our previous data, which showed that an EDC primer almost completely inactivates the gelatinolytic activity in HL created by different etchand-rinse adhesives (Mazzoni et al. 2013).

While the preservation of bond strength obtained with EDC pretreatment has already been shown after aging (Mazzoni et al. 2013), until now, the in situ gelatinolytic activity has only been evaluated in recently bonded HLs (Mazzoni et al. 2014). Thus, in the present study, we report, for the first time, the in situ quantification of gelatinolytic activity after $1 \mathrm{y}$ of storage, showing the efficacy of EDC pretreatment in the reduction of enzyme activity over time for both self-etch and etch-and-rinse adhesives (Table; Figs. 2 and 4).

Interestingly, this study also revealed a different enzyme inactivation pattern when comparing the self-etch with the etch-andrinse approach. At $\mathrm{T}_{0}$, CSE showed significantly lower activity than XPB. This confirms previous findings demonstrating that the self-etch approach may better protect dentin collagen against degradation, probably by maintaining hydroxyapatite crystals around collagen (De Munck et al. 2009, 2010; Mazzoni, Scaffa, et al. 2012; Mazzoni et al. 2015). However, the activity increased about 4-fold between $\mathrm{T}_{0}$ and $\mathrm{T}_{1 \mathrm{y}}$.

There are at least 2 potential explanations for this time-related increase in activity. We speculate that the self-etching primer created 10-MDP-calcium salts (Tian et al. 2016) that may have covered some but not all of the exposed collagen fibrils with relatively insoluble 10-MDP-calcium precipitates. These precipitates may have prevented access of the soluble gelatin substrate to the endogenous proteases, yielding 5.2\% hydrolysis at $\mathrm{T}_{0}$. During the storage, the salts may have slowly solubilized (Tian et al. 2016), thereby increasing the endogenous gelatinolytic activity of the $\mathrm{T}_{1 \text { y }}$ specimens. When EDC was applied to CSE primed dentin, the cross-linking agent inactivated all exposed proteases that were not covered by the 10-MDP-calcium precipitates, thereby lowering the gelatinolytic activity of the $\mathrm{T}_{0}$ specimens to be lower than controls (not treated with EDC).

Although the effectiveness of EDC at inactivating gelatinolytic activity within HLs created by self-etch and etch-andrinse adhesive systems at $\mathrm{T}_{0}$ was clearly demonstrated, an approximately 3 - to 4 -fold increase in activity could be detected after storage (Table). The inactivation of gelatinolytic activity in dentin matrix by cross-linking agents is thought to be due to conformational changes in the 3-dimensional structure of MMPs and probably other endogenous collagen degradation 
Table. Means of Percentage of MMP Activity (\%) and Standard Deviation (SD) Expressed by HLs Created with 2 Adhesives (Compositions Are Reported as Disclosed by Manufacturers) with and without EDC Pretreatment after the 2 Time Periods, as Revealed by In Situ Gelatin Zymography.

\begin{tabular}{|c|c|c|c|}
\hline \multirow[b]{2}{*}{ Adhesive System and Composition } & \multirow[b]{2}{*}{ EDC Pretreatment } & \multicolumn{2}{|c|}{$\%$ of MMP Activity of the HL } \\
\hline & & $\mathrm{T}_{0}$ & $T_{1 y}$ \\
\hline $\begin{array}{l}\text { Clearfil SE Bond } \\
\text { Bisphenol A diglycidylmethacrylate } \\
\text { 2-Hydroxyethyl methacrylate } \\
\text { 10-Methacryloyloxydecyl dihydrogen phosphate } \\
\text { Hydrophobic aliphatic methacrylate } \\
\text { Colloidal silica } \\
\text { dl-Camphorquinone } \\
\text { Initiators } \\
\text { Accelerators }\end{array}$ & Control & $0.01 \pm 0.0^{\mathrm{Aal}}$ & $6.7 \pm 0.8^{\mathrm{Aa} 2}$ \\
\hline $\begin{array}{l}\text { XP Bond } \\
\text { Carboxylic acid-modified dimethacrylate (TCB resin) } \\
\text { Phosphoric acid-modified acrylate resin (PENTA) } \\
\text { Urethane dimethacrylate (UDMA) } \\
\text { Triethyleneglycol dimethacrylate (TEGDMA) } \\
\text { 2-Hydroxyethylmethacrylate (HEMA) } \\
\text { Butylated benzenediol (stabilizer) } \\
\text { Ethyl-4-dimethylaminobenzoate } \\
\text { Camphorquinone } \\
\text { Nanofiller } \\
\text { t-Butanol }\end{array}$ & $\begin{array}{l}\text { EDC } \\
\text { Control }\end{array}$ & $\begin{array}{l}2.8 \pm 0.2^{\mathrm{Aal}} \\
\mid 4.7 \pm 2.0^{\mathrm{Bbl}}\end{array}$ & $\begin{array}{l}7.8 \pm 1.0^{\mathrm{Aa} 2} \\
13.6 \pm 2.0^{\mathrm{Bb} 1}\end{array}$ \\
\hline
\end{tabular}

For comparing the I-ethyl-3-(3-dimethylaminopropyl) carbodiimide $\mathrm{HCl}(\mathrm{EDC})$ pretreatment, means with the same superscript uppercase letters within the same vertical column for each adhesive system (Clearfil SE Bond and XP Bond) do not show a statistically significant difference $(P>0.05)$. For comparing the adhesive systems, means with the same superscript lowercase letters within the same vertical column for each EDC pretreatment (EDC and control) are not significantly different $(P>0.05)$. For comparison between the 2 time periods, groups in each row that are labeled with the same numerical superscripts are not significantly different $(P>0.05)$. HL, hybrid layer; MMP, matrix metalloproteinase.

enzymes (Busenlehner and Armstrong 2005; Liu et al. 2011; Mazzoni et al. 2013). In fact, it has been proposed that crosslinking may cause conformational change in the active site of the enzyme that may inhibit substrate binding or may contribute to enzyme silencing via allosteric control of noncatalytic domains (Liu et al. 2011; Frassetto et al. 2016).

Since the enzymes do not turn over in dentin, it has been speculated that their inactivation should last for a long time and may be even more effective than enzyme inhibitors (Cova et al. 2011; Tjäderhane et al. 2013). Some cross-linkers have been shown to stabilize completely demineralized dentin organic matrix mechanical properties over a prolonged $(12 \mathrm{mo})$ time (Castellan et al. 2011). However, there is no evidence that the catalytic domain of collagenolytic MMPs can be cross-linked to inactivate their functions. Several studies have demonstrated either minor (nonsignificant) or even significant time-dependent reduction in bond strength with EDC (Bedran-Russo et al. 2010; Mazzoni et al. 2013; Singh et al. 2015) and other crosslinkers (Cova et al. 2011; Hass et al. 2016). Although this reduction may be caused by the hydrolytic degradation of the adhesive component, the time-related loss of a cross-linker effect on collagenases cannot be ruled out.

Together with the significantly increased enzyme activity in $\mathrm{T}_{1 \mathrm{y}}$ samples in this study, the irreversible nature of the crosslinking effect on enzyme functional activity in the HL may be questioned. Both etch-and-rinse (Mazzoni et al. 2006) and selfetch (Nishitani et al. 2006) adhesives can cause a dramatic increase of dentin endogenous enzyme activities, indicating that the experiments evaluating the dentin matrix without adhesives do not fully correlate to the conditions in the HL. Longer aging of the $\mu$ TBS samples (e.g., $24 \mathrm{mo}$ ) could help to clarify the effect of EDC over time.

In conclusion, our results support the previous studies of the positive effects of EDC to dentin collagenolytic activity but also indicate that the effect may not be permanent. Further in vitro and in vivo studies are needed to better clarify the efficacy of EDC and other cross-linkers over time in relation to the different adhesive strategies.

\section{Author Contributions}

A. Mazzoni, contributed to conception, design, data analysis, and interpretation, drafted and critically revised the manuscript; V. Angeloni, contributed to conception, design, data analysis, and interpretation, drafted the manuscript; N. Sartori, contributed to data analysis and interpretation, drafted the manuscript; S. Duarte Jr., T. Maravic, contributed to data analysis and interpretation, critically revised the manuscript; L. Tjäderhane, D.H. Pashley, F.R. Tay, L. Breschi, contributed to conception, design, data analysis, and interpretation, critically revised the manuscript. All authors gave final approval and agree to be accountable for all aspects of the work.

\section{Acknowledgments}

The authors thank Mr Aurelio Valmori for technical assistance. The study was partially supported with MIUR grants (Italy). The 
authors declare no potential conflicts of interest with respect to the authorship and/or publication of this article.

\section{References}

Bedran-Russo AK, Pashley DH, Agee K, Drummond JL, Miescke KJ. 2008 Changes in stiffness of demineralized dentin following application of collagen crosslinkers. J Biomed Mater Res B Appl Biomater. 86(2):330-334.

Bedran-Russo AK, Pauli GF, Chen S-N, McAlpine J, Castellan CS, Phansalkar RS, Aguiar TR, Vidal CM, Napotilano JG, Nam JW. 2014. Dentin biomodification: strategies, renewable resources and clinical applications. Dent Mater. 30(1):62-76.

Bedran-Russo AK, Vidal CM, Dos Santos PH, Castellan CS. 2010. Long-term effect of carbodiimide on dentin matrix and resin-dentin bonds. J Biomed Mater Res B Appl Biomater. 94(1):250-255.

Breschi L. 2013. Chlorhexidine application to stabilize the adhesive interface: why and how? J Adhes Dent. 15(5):492.

Breschi L, Cammelli F, Visintini E, Mazzoni A, Vita F, Carrilho M, Cadenaro M, Foulger S, Mazzotti G, Tay FR, et al. 2009. Influence of chlorhexidine concentration on the durability of etch-and-rinse dentin bonds: a 12-month in vitro study. J Adhes Dent. 11(3):191-198.

Breschi L, Martin P, Mazzoni A, Nato F, Carrilho M, Tjäderhane L, Visintini E, Cadenaro M, Tay FR, De Stefano Dorigo E, et al. 2010. Use of a specific MMP-inhibitor (galardin) for preservation of hybrid layer. Dent Mater. 26(6):571-578.

Breschi L, Mazzoni A, Nato F, Carrilho M, Visintini E, Tjäderhane L, Ruggeri A Jr, Tay FR, Dorigo Ede S, Pashley DH. 2010. Chlorhexidine stabilizes the adhesive interface: a 2-year in vitro study. Dent Mater. 26(4):320-325.

Breschi L, Mazzoni A, Ruggeri A, Cadenaro M, Di Lenarda R, De Stefano Dorigo E. 2008. Dental adhesion review: aging and stability of the bonded interface. Dent Mater. 24(1):90-101.

Busenlehner LS, Armstrong RN. 2005. Insights into enzyme structure and dynamics elucidated by amide H/D exchange mass spectrometry. Arch Biochem Biophys. 433(1):34-46.

Carrilho MR, Carvalho RM, De Goes MF, di Hipólito V, Geraldeli S, Tay FR, Pashley DH, Tjäderhane L. 2007. Chlorhexidine preserves dentin bond in vitro. J Dent Res. 86(1):90-94.

Carrilho MR, Carvalho RM, Sousa EN, Nicolau J, Breschi L, Mazzoni A, Tjäderhane L, Tay FR, Agee K, Pashley DH. 2010. Substantivity of chlorhexidine to human dentin. Dent Mater. 26(8):779-785.

Castellan CS, Bedran-Russo AK, Karol S, Pereira PN. 2011. Long-term stability of dentin matrix following treatment with various natural collagen crosslinkers. J Mech Behav Biomed Mater. 4(7):1343-1350.

Cova A, Breschi L, Nato F, Ruggeri A Jr, Carrilho M, Tjäderhane L, Prati C, Di Lenarda R, Tay FR, Pashley DH, et al. 2011. Effect of UVA-activated riboflavin on dentin bonding. J Dent Res. 90(12):1439-1445.

De Munck J, Mine A, Van den Steen PE, Van Landuyt KL, Poitevin A, Opdenakker G, Van Meerbeek B. 2010. Enzymatic degradation of adhesive-dentin interfaces produced by mild self-etch adhesives. Eur J Oral Sci. 118(5):494-501.

De Munck J, Van den Steen PE, Mine A, Van Landuyt KL, Poitevin A, Opdenakker G, Van Meerbeek B. 2009. Inhibition of enzymatic degradation of adhesive-dentin interfaces. J Dent Res. 88(12):1101-1106.

Frassetto A, Breschi L, Turco G, Marchesi G, Di Lenarda R, Tay FR, Pashley DH, Cadenaro M. 2016. Mechanisms of degradation of the hybrid layer in adhesive dentistry and therapeutic agents to improve bond durability: a literature review. Dent Mater. 32(2):e41-e53.

Hass V, Luque-Martinez IV, Gutierrez MF, Moreira CG, Gotti VB, Feitosa VP, Koller G, Otuki MF, Loguercio AD, Reis A. 2016. Collagen cross-linkers on dentin bonding: stability of the adhesive interfaces, degree of conversion of the adhesive, cytotoxicity and in situ MMP inhibition. Dent Mater. 32(6):732-741.

Lee JM, Edwards HH, Pereira CA, Samii SI. 1996. Crosslinking of tissuederived biomaterials in 1-ethyl-3-(3-dimethylaminopropyl)-carbodiimide (EDC). J Mater Sci Mater Med. 7(9):531-541.

Liu Y, Tjäderhane L, Breschi L, Mazzoni A, Li N, Mao J, Pashley DH, Tay FR. 2011. Limitations in bonding to dentin and experimental strategies to prevent bond degradation. J Dent Res. 90(8):953-968.

Matuda LS, Marchi GM, Aguiar TR, Leme AA, Ambrosano GM, BedranRusso AK. 2016. Dental adhesives and strategies for displacement of water/ solvents from collagen fibrils. Dent Mater. 32(6):723-731.
Mazzoni A, Angeloni V, Apolonio FM, Scotti N, Tjäderhane L, TezvergilMutluay A, Di Lenarda R, Tay FR, Pashley DH, Breschi L. 2013. Effect of carbodiimide (EDC) on the bond stability of etch-and-rinse adhesive systems. Dent Mater. 29(10):1040-1047.

Mazzoni A, Apolonio FM, Saboia VP, Santi S, Angeloni V, Checchi V, Curci R, Di Lenarda R, Tay FR, Pashley DH, et al. 2014. Carbodiimide inactivation of MMPs and effect on dentin bonding. J Dent Res. 93(3):263-268.

Mazzoni A, Nascimento FD, Carrilho M, Tersariol I, Papa V, Tjäderhane L, Di Lenarda R, Tay FR, Pashley DH, Breschi L. 2012. MMP activity in the hybrid layer detected with in situ zymography. J Dent Res. 91(5):467-472.

Mazzoni A, Pashley DH, Nishitani Y, Breschi L, Mannello F, Tjäderhane L, Toledano M, Pashley EL, Tay FR. 2006. Reactivation of inactivated endogenous proteolytic activities in phosphoric acid-etched dentine by etch-andrinse adhesives. Biomaterials. 27(25):4470-4476.

Mazzoni A, Scaffa P, Carrilho M, Tjäderhane L, Di Lenarda R, Polimeni A, Tezvergil-Mutluay A, Tay FR, Pashley DH, Breschi L. 2012. Effects of etch-and-rinse and self-etch adhesives on dentin MMP-2 and MMP-9. J Dent Res. 92(1):82-86.

Mazzoni A, Tjäderhane L, Checchi V, Di Lenarda R, Salo T, Tay FR, Pashley DH, Breschi L. 2015. Role of dentin MMPs in caries progression and bond stability. J Dent Res. 94(2):241-251.

Nishitani Y, Yoshiyama M, Wadgaonkar B, Breschi L, Mannello F, Mazzoni A, Carvalho RM, Tjäderhane L, Tay FR, Pashley DH. 2006. Activation of gelatinolytic/collagenolytic activity in dentin by self-etching adhesives. Eur J Oral Sci. 114(2):160-166.

Pashley DH, Tay FR, Yiu C, Hashimoto M, Breschi L, Carvalho RM, Ito S. 2004. Collagen degradation by host-derived enzymes during aging. J Dent Res. 83(3):216-221.

Ricci HA, Sanabe ME, de Souza Costa CA, Pashley DH, Hebling J. 2010. Chlorhexidine increases the longevity of in vivo resin-dentin bonds. Eur J Oral Scie. 118(4):411-416.

Scheffel D, Delgado CC, Soares DG, Basso FG, de Souza Costa CA, Pashley DH, Hebling J. 2015. Increased durability of resin-dentin bonds following cross-linking treatment. Oper Dent. 40(5):533-539.

Scheffel DL, Hebling J, Scheffel RH, Agee KA, Cadenaro M, Turco G, Breschi L, Mazzoni A, de Souza Costa CA, Pashley DH. 2014. Stabilization of dentin matrix after cross-linking treatments, in vitro. Dent Mater. 30(2):227233.

Scheffel DL, Hebling J, Scheffel RH, Agee K, Turco G, de Souza Costa CA, Pashley D. 2014. Inactivation of matrix-bound matrix metalloproteinases by cross-linking agents in acid-etched dentin. Oper Dent. 39(2):152-158.

Seseogullari-Dirihan R, Apollonio F, Mazzoni A, Tjaderhane L, Pashley D, Breschi L, Tezvergil-Mutluay A. 2016. Use of crosslinkers to inactivate dentin MMPs. Dent Mater. 32(3):423-432.

Singh S, Nagpal R, Tyagi SP, Manuja N. 2015. Effect of EDTA conditioning and carbodiimide pretreatment on the bonding performance of all-in-one self-etch adhesives. Int J Dent. 2015:141890.

Suppa P, Breschi L, Ruggeri A, Mazzotti G, Prati C, Chersoni S, Di Lenarda R, Pashley DH, Tay FR. 2005. Nanoleakage within the hybrid layer: a correlative FEISEM/TEM investigation. J Biomed Mater Res B Appl Biomater. 73(1):7-14.

Tezvergil-Mutluay A, Mutluay MM, Agee KA, Seseogullari-Dirihan R, Hoshika T, Cadenaro M, Breschi L, Vallittu P, Tay FR, Pashley DH. 2012. Carbodiimide cross-linking inactivates soluble and matrix-bound MMPs, in vitro. J Dent Res. 91(2):192-196.

Tezvergil-Mutluay A, Mutluay MM, Gu LS, Zhang K, Agee KA, Carvalho RM, Manso A, Carrilho M, Tay FR, Breschi L, et al. 2011. The anti-MMP activity of benzalkonium chloride. J Dent. 39(1):57-64.

Tian FC, Wang XY, Huang Q, Niu LN, Mitchell J, Zhang ZY, Prananik C, Zhang L, Chen JH, Breschi L, et al. 2016. Effect of nanolayering of calcium salts of phosphoric acid ester monomers on the durability of resindentin bonds. Acta Biomater. 38:190-200. Corrigendum published Acta Biomater. 2017;49:605.

Timkovich R. 1977. Detection of the stable addition of carbodiimide to proteins. Anal Biochem. 79(1-2):135-143.

Tjäderhane L, Nascimento FD, Breschi L, Mazzoni A, Tersariol IL, Geraldeli S, Tezvergil-Mutluay A, Carrilho MR, Carvalho RM, Tay FR, et al. 2013. Optimizing dentin bond durability: control of collagen degradation by matrix metalloproteinases and cysteine cathepsins. Dent Mater. 29(1):116-135 